COMENTARIOS Y REVISIONES

Rev Chil Salud Pública 2013 Vol 17 (2): 167-169

\title{
Diplomacia en Salud Global: Un reto para la nueva agenda de desarrollo
}

\author{
Diplomacy in Global health:
}

A CHALlENGE FOR THE NEW DEVELOPMENT AGENDA

Estamos atravesando un momento histórico donde se redefine una nueva alianza mundial para el desarrollo. Los modelos de desarrollo de cada país no pueden obviar la existencia de otras experiencias en curso que han tenido aciertos y desaciertos.

En el mundo está aumentando el consenso valorativo donde se sugiere que para enfrentar nuevos y viejos desafíos "se requiere un nuevo modelo de desarrollo basado en un cambio estructural para la igualdad y la sostenibilidad ambiental"1. Es en este contexto donde resulta crucial reforzar la importancia de los bienes públicos globales esenciales, como el comercio justo, la estabilidad del sistema financiero internacional, la sostenibilidad ambiental y la cobertura universal de salud, entre otros.

Como nunca antes se necesita de pactos globales, donde todos los Estados compartan herramientas, normas y políticas para una estrategia de desarrollo donde se integre el crecimiento económico, la equidad social y la protección social, tal como se recomienda en el documento "El Futuro que Queremos", aprobado en la Conferencia de las Naciones Unidas sobre el Desarrollo Sostenible (Río + 20)², realizada en Río de Janeiro, Brasil, en pasado 2012.

\section{ENFOQUE RENOVADO DE LA DIPLOMACIA EN SALUD GLOBAL}

Es bien conocida la relación directa que tiene la salud en el desarrollo y viceversa, el impacto que el desarrollo tiene para el logro de una mejor calidad de vida y salud para todos.

La inclusión de la salud en los pactos globales para una nueva agenda de desarrollo requiere una combinación de esfuerzos, bien articulados, entre los sectores de salud y servicio exterior. No siempre los representantes del sector salud son incluidos en las delegaciones que negocian los acuerdos internacionales que tienen relación con las estrategias de desarrollo global. Muchas veces, al interior de los países mismos, tampoco se promueven espacios de deliberación y posicionamiento sobre los temas relacionados con agendas globales de desarrollo, tal como está sucediendo con el proceso de construcción de una nueva agenda global de desarrollo post-2015.

La diplomacia en la salud global tiene en nuestros tiempos una importancia crucial en materia de desarrollo. Como conocemos, la diplomacia hace referen- 
cia a la comprensión, la voluntad de diálogo y el entendimiento aplicados a las relaciones internacionales. Por otro lado, en la Constitución de la Organización Mundial de la Salud (OMS) ${ }^{3}$, adoptada en 1946, se señala que "la salud de todos los pueblos es una condición fundamental para lograr la paz y la seguridad, y depende de la más amplia cooperación de las personas y de los Estados".

Si bien la diplomacia y la salud han marchado históricamente de la mano, desde los orígenes mismos de ambas disciplinas, es en los últimos años que el enfoque sobre "diplomacia en salud global" ha adquirido una mayor y renovada dimensión. Esto se ha debido, entre otros factores, al acelerado proceso de globalización, lo cual sigue repercutiendo en todos los ámbitos del desarrollo humano, pero también a los múltiples cambios tecnológicos, al desarrollo de la ciencia, y a las variadas situaciones económicas y políticas que en los últimos dos decenios están impactando las relaciones establecidas entre los Estados.

Es destacable la importancia que la salud ha adquirido en las agendas de política mundial. Pero se trata de un asunto que necesita una mayor valorización por los Estados para que, en la práctica, y no solo en teoría, pueda ocupar el espacio que merece.

Se trata de un asunto que trasciende las fronteras de los países y donde, para su abordaje integral, se relaciona con una gama amplia de sectores ligados al desarrollo, como son, agricultura, economía, relaciones exteriores, defensa, ambiente, entre otros. Esto hace del tema "diplomacia en salud global", o "diplomacia sanitaria" como otros prefieren llamar, un asunto cada vez más atractivo y complejo.

La importancia de la interfaz entre diplomacia y salud seguirá aumentando. Si bien se requiere un mayor esfuerzo en este campo, tal como señalamos anteriormente, vemos como un número creciente de diplomáticos se interiorizan en los contenidos sanitarios y, por otro lado, son más que antes los profesionales y técnicos de la salud que tratan de armarse con herramientas, conocimientos y capacidades críticas necesarias para abordar los intereses nacionales de la salud en diferentes ámbitos internacionales.

Avanzado ya el 2013 nos encontramos con una amplia agenda política internacional donde la salud debe ocupar un espacio preponderante. La participación coordinada entre las autoridades de salud y los responsables de la política exterior en los países es imprescindible. La "diplomacia en la salud global" se enfrenta a una nueva oportunidad de actuación y demostración de la estrecha interrelación entre estos dos componentes.

\section{UNA NUEVA AGENDA GLOBAL DE DESARROLLO PARA EL POST 2015}

Estamos muy cerca de que se cumpla el plazo para alcanzar los Objetivos de Desarrollo del Milenio (ODM). Es probable que algunos de estos objetivos no sean plenamente alcanzados. Esto no disminuye en nada la importancia que este acuerdo global ha tenido en los últimos años para aunar voluntades y tomar decisiones a favor del mejoramiento de las condiciones de vida y bienestar de las personas y las familias en situaciones de pobreza y pobreza extrema. Con las informaciones y datos que se disponen actualmente se pueden demostrar avances y resultados significativos a nivel mundial desde el año 2000 hasta el presente ${ }^{4}$.

El reto que se tiene por delante es la construcción de una nueva agenda global de desarrollo donde, al igual que los ODM, se convierta en un instrumento orientador para continuar construyendo un futuro mejor para todos los ciudadanos. Es esta situación la que configura el principal ámbito de contexto y coyuntura en política exterior para el desarrollo y en el campo de la "diplomacia en salud global".

Es un momento de reflexión y debate. Se están realizando en el mundo una gran cantidad de reuniones y produciendo una variedad de documentos donde se abordan los ejes principales que deberían guiar el desarrollo futuro en todos nuestros países, ya sean países desarrollados o en vías de desarrollo.

Las delegaciones de los estados que participan en estas reuniones principalmente provienen de los Ministerios de Relaciones Exteriores, de Economía, y algunos de las entidades nacionales relacionadas con los problemas ambientales. Poca ha sido hasta ahora la participación del sector salud. Debiese producirse en los próximos tiempos (2013-2014) un trabajo más efectivo por parte de "los diplomáticos" que participan en estos procesos, ya sea diplomáticos propiamente dicho, que provienen de los Ministerios de Relaciones Exte- 
riores, como autoridades de salud y de otras instituciones relacionadas con la salud en capacidad de "hacer diplomacia", de negociar los contenidos de la nueva agenda y establecer los pactos correspondientes.

\section{CÓMO COLOCAR SALUD EN ESTA NUEVA AGENDA DE DESARROLLO}

Por lo que se está observando en el plano internacional, la propuesta de "Cobertura Universal de Salud" está teniendo un fuerte destaque, tanto en el ámbito multilateral de actuación, como también por parte de otros actores nacionales e internacionales comprometidos con el desarrollo sanitario.

La cobertura universal de salud podría constituir uno de los objetivos de la nueva agenda de desarrollo post-2015. Se trataría de esta forma de garantizar el derecho a la salud para todos. La cobertura universal constituye un objetivo al cual deben estar orientados los sistemas de salud. Tiene dos componentes principales. El acceso de todas las personas a servicios integrales de salud basados en las necesidades, y su protección financiera contra los riesgos originados por la pérdida de salud. Se trata de un proceso dinámico que se desarrolla trabajando en tres dimensiones: a) la proporción de la población con acceso a servicios de salud, b) el rango y la calidad de los servicios proporcionados, y c) la disminución o eliminación de las barreras financieras para dicho acceso.

A finales del año 2012 la Asamblea General de Naciones Unidas aprobó una resolución en la que exhorta a los países a avanzar hacia la cobertura universal de salud. Se trata de un paso importante para llamar la atención colectiva internacional respecto a la importancia que esto tiene en el marco de lucha contra la pobreza y para el desarrollo sostenible, con equidad y justicia social.

Tal acuerdo alcanzado en la Asamblea General de Naciones Unidas aboga, asimismo, por sistemas de salud que sean financiados a través de impuestos y se establece como recomendación donde se señala que, si los usuarios deben realizar algún pago por los servicios de salud que reciben, éste sea reducido y no suponga una barrera para el acción a la atención.

La OMS estima que cada año unos 100 millones de personas caen en la pobreza como conse- cuencia de los pagos que deben realizar para obtener atención médica. Por esto la OMS recomienda con fuerza que los gobiernos deben financiar sus sistemas de salud a partir de un esquema de prepago, en el que, a través de impuestos o contribuciones, los ciudadanos hagan abonos a través del tiempo y accedan a servicios sanitarios cuando los necesiten, sin que existan limitantes para algún segmento de la población y utilizarlos no implique una afectación a la economía familiar derivada de altos cobros.

Sin duda, la resolución de la Asamblea General de las Naciones Unidas es un paso importante a nivel mundial, que servirá como base para que los países garanticen una asistencia equitativa y económicamente accesible para todos los ciudadanos.

Es destacable el trabajo de los países que integran el "Grupo de Política Exterior y Salud Global", compuesto por Brasil, Francia, Indonesia, Noruega, Senegal, Sudáfrica, Tailandia, México y Bosnia Herzegovina.

La cobertura universal de salud es un componente crítico del desarrollo sostenible y una expresión práctica para asegurar la equidad y el derecho a la salud. Precisamente, por estas características, la convierte en un tema de especial significado para su inclusión en la nueva agenda de desarrollo post-2015 y un espacio muy notorio para la articulación de los conocimientos y capacidades críticas necesarias para la práctica de la "diplomacia en la salud global".

\section{REFERENCIAS}

1. CEPAL. "Desarrollo sostenible en América Latina y el Caribe". Seguimiento de la agenda de las Naciones Unidas para el desarrollo post-2015 y Río+20. Santiago, Chile, marzo 2013.

2. ONU. "El Futuro que Queremos". Doc.A/ CONF.216/L.1. Conferencia de las Naciones Unidas sobre el Desarrollo Sostenible (Río + 20).Río de Janeiro, Brasil. Junio 2012.

3. OPS/OMS. Documentos Básicos de la Organización Panamericana de la Salud - Decimoséptima edición. Documento oficial No. 325. Washington D.C. 20037, E.U.A. 2007.

4. ONU. Objetivos de Desarrollo del Milenio (1000 días para actuar). http://www.un.org/es/millenniumgoals/. New York, USA. 2013. 